\title{
Os FRBR e a escolha do ponto de acesso pessoal
}

\author{
Naira Christofoletti Silveira
}

Mestre em Ciência da Informação, PUC-Campinas. Professora no curso Biblioteconomia, Centro Universitário Assunção, UNIFAI

Maria de Fátima Gonçalves Moreira Tálamo

Professora colaboradora do Programa de PósGraduação em Ciência da Informação, ECA/USP

Análise dos procedimentos para a escolha dos pontos de acesso de responsabilidade pessoal associados aos conceitos apresentados nos Requisitos Funcionais para Registros Bibliográficos (FRBR). Trata-se de uma investigação teórica que se vale das pesquisas bibliográfica e documental para elaborar um quadro comparativo entre as regras catalográficas e os conceitos apresentados nos FRBR. Neles, as atividades dos usuários devem ser facilitadas, exigindo maior empenho do profissional para determinar quais pontos de acessos são compatíveis para atender às necessidades de seu público.

Palavras-chave: Requisitos Funcionais para Registros Bibliográficos (FRBR); Ponto de acesso pessoal; Catalogação.

\section{The FRBR and the choice of the personal access points}

This work aims to analyse the procedures to choose the access points of personal responsibility of the bibliographic records, in order to relate them to the concepts shown in the FRBR. The present work is characterized as a theoretical search and the investigation resorts to deductive approach to analyse the rules and the internationally accepted principles utilized in the choice of the access points. With the FRBR the rules have to be stipulated to facilitate the user activities. In this way, the professional of information will pay more efforts to determine which the access points for the user are. 
Keywords: Functional Requirements for Bibliographic Records - FRBR; Access points; Cataloguing.

Recebido em 03.12.2007 Aceito em 24.07.2009

\section{Introdução}

A Biblioteconomia possui uma vasta tradição na organização e na preservação dos registros do conhecimento, como se observa na própria história das bibliotecas. Por exemplo, já no terceiro milênio a.C. a biblioteca de Elba, na Síria, continha uma coleção organizada de 15 mil tábuas de argila, com textos administrativos, literários e científicos, e 15 tábuas pequenas com os resumos dos conteúdos dos documentos (SAGREDO; NUÑO' ${ }^{1}, 1994$ apud ORTEGA, 2004).

Mesmo isoladamente, os bibliotecários estipulavam padrões para a representação dos documentos. No entanto, com as mudanças na sociedade e na forma de produção do conhecimento, a padronização deixou de ser realizada em nível local e se expandiu para o nível internacional. Portanto, foram estabelecidos diversos documentos com os princípios, as diretrizes e as regras para a catalogação, propiciando maior precisão, controle e intercâmbio de dados bibliográficos.

Em meio às transformações de regras e padrões para a catalogação, é possível verificar os documentos emanados de eventos institucionais da área que influenciam e direcionam a catalogação em âmbito internacional. São eles: os Princípios de Paris, o Código de Catalogação Anglo-Americano (CCAA), os Requisitos Funcionais para Registros Bibliográficos (FRBR) e a Declaração de Princípios Internacionais de Catalogação, aqui denominados como documentos normativos.

Nesse contexto, com o objetivo de comparar os FRBR com as regras de catalogação que determinam a escolha dos pontos de acesso de responsabilidade pessoal, o presente artigo distribui-se em quatro partes, além dessa introdução. Na primeira apresenta-se uma síntese dos FRBR, focalizando seus conceitos mais relevantes para os objetivos do presente artigo. Na segunda, discorre-se sobre as funções que um catálogo deve desempenhar, conforme apresentado nos documentos normativos. $\mathrm{Na}$ terceira parte é exposta uma análise sobre as regras que determinam a escolha do ponto de acesso para ilustradores e tradutores, comparando tais regras com os conceitos apresentados nos FRBR. Por fim, são exibidas as considerações finais.

\section{Os Requisitos Funcionais para Registros Bibliográficos - FRBR}

O primeiro objetivo que norteou o desenvolvimento dos Requisitos Funcionais para Registros Bibliográficos (FRBR) foi proporcionar um

\footnotetext{
1 SAGREDO, F.; NUÑO, M. V. En los orígenes de la Biblioteconomía y Documentación: Ebla. Documentación de las Ciencias de la Información, Madrid, n. 17, p. 123-129, 1994.
} 
quadro estruturado, claramente definido, para relacionar os dados contidos nos registros bibliográficos com as necessidades dos usuários desses registros. Ou seja, os FRBR fazem uma abordagem centrada no usuário, analisam quais requisitos de dados o usuário utiliza para realizar a busca e o que ele espera encontrar de informação no registro bibliográfico. O segundo objetivo foi recomendar um nível básico de funcionalidade dos registros bibliográficos criados pelas agências bibliográficas nacionais (INTERNATIONAL FEDERATION OF LIBRARY ASSOCIATIONS - IFLA, 1998).

Para fins do presente artigo, os conceitos relevantes presentes nos FRBR são as entidades obra e expressão, apresentadas a seguir no tópico "as entidades", e as tarefas dos usuários encontrar e identificar, explanadas no tópico "as funções do catálogo".

\subsection{As entidades}

Peter Chen (1990, p. 20) define entidade como "[...] uma 'coisa' que pode ser distintamente identificada". Nos FRBR, as entidades são vistas como objetos-chave que interessam ao usuário do registro bibliográfico. Ao todo, os FRBR apresentam dez entidades, divididas em três grupos:

1. Grupo 1 - as entidades que representam os produtos de trabalho intelectual ou artístico: obra, expressão, manifestação e item;

2. Grupo 2 - as entidades que representam os responsáveis pelo conteúdo, pela produção, disseminação e guarda das entidades do primeiro grupo: pessoa e entidade coletiva;

3. Grupo 3 - as entidades que representam os assuntos de uma obra: conceito, objeto, evento e lugar.

A seguir, uma síntese sobre as entidades obra e expressão, do Grupo 1.

A primeira entidade apresentada nos FRBR é a

obra. Ela é abstrata e reconhecida através de suas expressões. A obra propriamente dita existe apenas no conteúdo em comum de suas várias expressões. Quando se fala da Ilíada de Homero como uma obra, o ponto de referência não é uma narração ou texto específico da obra, mas a criação intelectual inscrita em suas várias expressões. Quando a modificação de uma obra envolve um esforço intelectual, a obra passa a ser considerada uma nova obra. Os FRBR consideram que as paráfrases, os reescritos, as adaptações para crianças, as paródias, as variações musicais sobre um tema e as transcrições livres de uma composição musical envolvem um esforço intelectual e, portanto, são consideradas novas obras (IFLA, 1998).

A expressão é a segunda entidade apresentada. Trata-se da realização intelectual ou artística de uma obra sob a forma alfa-numérica, musical ou de notação coreográfica, som, imagem, objeto, movimento etc., ou qualquer combinação de tais formas. Uma expressão é a forma 
intelectual ou artística específica que assume uma obra a cada vez em que é "realizada". Qualquer mudança no conteúdo intelectual ou artístico constitui mudança na expressão. A expressão de uma obra é materializada através de outra entidade, a manifestação (IFLA, 1998).

Por serem abstrações, há dificuldade em delimitar obra e expressão, assim como o que deve ser definido como uma nova obra ou uma nova expressão. A figura abaixo (FIG. 1) busca esclarecer os limites entre obra e expressão.

\section{Família de Obras}

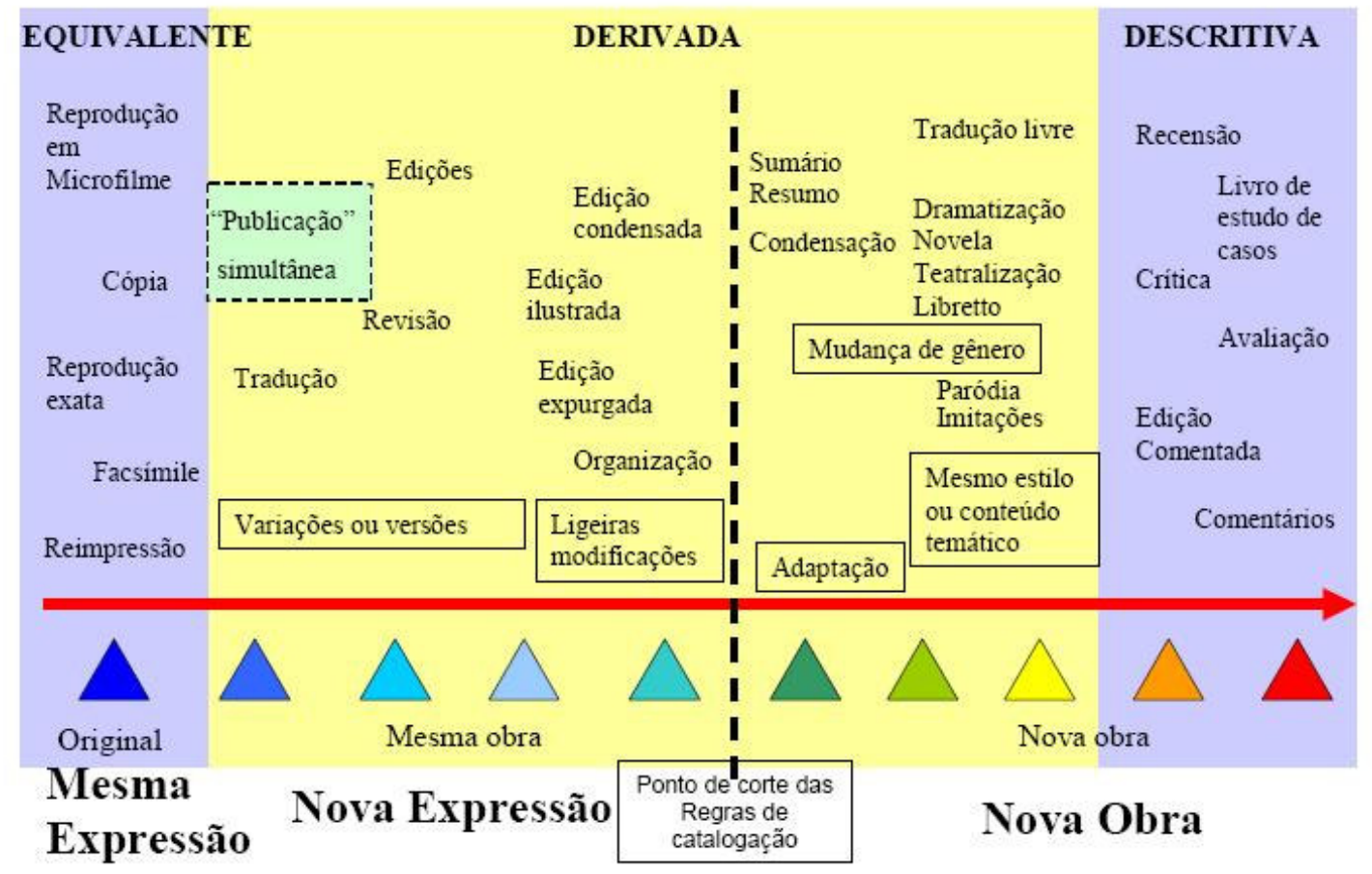

FIGURA 1 - Limites entre obra e expressão

Fonte: TILLETT (2003, p. 4).

A obra e a expressão permanecem idênticas caso haja apenas alteração do suporte da informação, como, por exemplo, reprodução em microfichas, cópias ou reimpressões. Porém, quando há alterações no texto, sejam elas provenientes de grandes ou pequenos esforços intelectuais, surge uma nova expressão de uma mesma obra. Exemplificando, embora a tradução seja uma atividade que exige grande esforço intelectual, no âmbito dos FRBR equivale a ligeiras modificações na obra original, resultando ambas em novas expressões.

Não há limites quantitativos para o surgimento de novas expressões. Como a tradução e a revisão de uma expressão resultam em novas expressões, infere-se que os FRBR propiciam um novo olhar, outra abordagem ou ponto de vista, sobre a função de tradutor e de revisor, uma vez que eles respondem também pelo surgimento de uma nova expressão. As "edições", igualmente, são tidas como novas expressões, 
embora nem sempre uma nova edição apresente alterações em relação à anterior. Geralmente, as novas edições resultam de revisão, atualização ou ampliação do conteúdo. Porém, algumas vezes as editoras fazem apenas a reimpressão de textos, designando-a como uma nova edição. Nesse caso, trata-se apenas de um apelo comercial. Portanto, para os FRBR, os conceitos ainda não se encontram efetivamente providos de consistência qualitativa.

De fato, parece-nos que o limite entre expressão e obra está no esforço intelectual que propõe acréscimo; ou seja, quando uma idéia original, algo novo ou diferente é acrescentado à obra, independente de apreciação valorativa. Uma adaptação requer esforço intelectual e criatividade para adequar uma obra a um outro universo (teatro, crianças). A idéia do autor da obra a ser adaptada é alterada, por isso a adaptação se transforma em uma nova obra. Há modificações das idéias do autor original.

A tradução, igualmente, requer um grande esforço intelectual, principalmente para alguns autores literários. Entretanto, o tradutor não pode ser muito original, ele deve seguir as idéias do autor que está traduzindo. Como não há inclusões de idéias originais ou criativas na tradução, ela é designada como uma nova expressão.

\subsection{As funções do catálogo}

As funções atribuídas a um catálogo, apresentadas nos Princípios de Paris, afirmam que o catálogo deve ser um instrumento eficaz para determinar se a biblioteca possui um determinado livro quando for especificado seu autor, título ou um substituto conveniente do título. $E$, ainda, deve determinar quais obras de um determinado autor e quais edições de uma obra existem na biblioteca (DECLARACIÓN..., 2004).

Tais funções, estabelecidas em 1961, se assemelham àquelas propostas por Cutter, publicadas inicialmente em 1876. Cutter ${ }^{2}$ (1972 apud MEY, 1995, p. 9) propõe três objetivos para o catálogo:

1. Permitir a uma pessoa encontrar um livro do qual ou
(A) o autor
(B) o título
(C) o assunto
seja conhecido

2. Mostrar o que a biblioteca possui

(D) de um autor determinado

(E) de um assunto determinado

(F) de um tipo determinado de literatura

3. Ajudar na escolha de um livro

(G) de acordo com sua edição (bibliograficamente)

(H) de acordo com seu caráter (literário ou tópico).

Mesmo estipulados muito antes dos Princípios de Paris, os objetivos propostos por Cutter são mais abrangentes que as funções determinadas

\footnotetext{
${ }^{2}$ CUTTER, C. A. Rules for a dictionary catalog. 4 ed. Washigton, D.C.: Printing Office, 1904.
} 
nos Princípios; neles são incluídas as recuperações por assunto e por tipo de literatura. Percebe-se que nos Princípios de Paris são abordadas as atividades relativas à Representação Descritiva - autoria e título -, enquanto Cutter aborda as atividades relativas à Representação Descritiva e à Temática - autoria, título, assunto e tipo de literatura.

Mesmo publicados em 1876, os objetivos propostos por Cutter ainda são aceitos atualmente, influenciando, inclusive, as tarefas dos usuários (encontrar, identificar, selecionar e obter uma entidade) apresentadas nos FRBR (IFLA, 1998). Conforme já observado por Moreno (2006, p. 33), as tarefas dos usuários "[...] são fortemente inspiradas nos três objetivos do catálogo, propostos por Cutter".

Os FRBR são um modelo conceitual, e abordam tanto a Representação Descritiva quanto a Representação Temática; talvez esse seja o motivo de se aproximarem mais dos objetivos do catálogo proposto por Cutter do que das funções determinadas pelos Princípios de Paris.

A Declaração de Princípios Internacionais de Catalogação, substituta dos Princípios de Paris, também atribui funções ao catálogo. Como esta Declaração incorpora os conceitos dos FRBR, percebe-se que as funções determinadas por ela são mais amplas que as anteriores. Dentre seus cinco objetivos propostos, quatro se referem às tarefas dos usuários apresentadas pelos FRBR. Conforme esta Declaração, as funções do catálogo destinam-se a permitir ao usuário (IFLA, 2009):

1. Encontrar recursos bibliográficos numa coleção, utilizando atributos ou relações do recurso, para localizar um determinado recurso; para localizar conjuntos de recursos apresentando todos os recursos pertencentes à mesma obra, expressão ou manifestação; todas as obras e expressões de uma determinada pessoa, família ou entidade coletiva; todos os recursos de um determinado assunto; e todos os recursos definidos por outros critérios como língua, país de publicação, formato físico etc.;

2. Identificar um recurso bibliográfico ou agente, confirmando se a entidade descrita no registro corresponde à entidade procurada, e distinguir entidades com características similares;

3. Selecionar um recurso bibliográfico apropriado às suas necessidades;

4. Obter acesso a um exemplar descrito no registro por compra, empréstimo ou acesso remoto, ou obter um registro bibliográfico ou de autoridade;

5. Percorrer ou navegar um catálogo através da organização lógica da informação bibliográfica e da apresentação das formas; também deve ser possível aos usuários identificar as relações entre obras, expressões, manifestações e itens.

Nas funções definidas pela Declaração de Princípios Internacionais de Catalogação, especialmente na função obter um registro bibliográfico ou de autoridade, é possível verificar que o catalogador também é 
considerado um usuário. Isto porque o catalogador pode obter um registro bibliográfico para fins de cooperação de dados bibliográficos, ou pode obter um registro de autoridade para identificar o termo controlado para um nome. Entre as formas variantes de um mesmo autor, o catalogador necessita de auxílio para definir a sua forma padronizada. Dessa forma, o catalogador também é um usuário do catálogo, ainda que o catálogo seja usado com intuito profissional, como uma ferramenta de cooperação e de padronização de dados bibliográficos.

Observa-se também que a última função, permitir ao usuário percorrer ou navegar o catálogo, não está relacionada às tarefas dos usuários apresentadas nos FRBR, e sim aos relacionamentos propostos nos mesmos. Os relacionamentos entre as entidades, apresentados nos FRBR, têm a finalidade de estabelecer vínculos entre as entidades para que o usuário percorra o catálogo.

As funções do catálogo são alcançadas quando pontos de acesso são estipulados para os registros bibliográficos, pois através destes o usuário recupera o registro. Ou seja, o registro bibliográfico deverá conter os atributos e elementos que possibilitem ao usuário encontrar, identificar, selecionar e obter as entidades por ele desejadas, assim como percorrer o catálogo identificando outras entidades que se relacionam com a entidade buscada por ele.

\subsection{Análise das regras e dos conceitos}

A partir de uma investigação teórica, recorreu-se à pesquisa bibliográfica e documental para interpretar e comparar as regras de catalogação com os conceitos apresentados nos FRBR. Revelam-se, desta forma, os impactos dos FRBR nos procedimentos para a escolha dos pontos de acesso para responsabilidade pessoal.

Para cada tipo de atividade (função) exercida por uma pessoa é designada uma regra específica. Cada regra estabelece os pontos de acesso de acordo com a função, e, de certa forma, define a importância da contribuição intelectual ou artística de uma pessoa ou entidade coletiva para uma obra ou expressão. Devido à grande quantidade de regras, serão analisadas as questões de ponto de acesso para a responsabilidade mista entre o autor do texto original e o seu tradutor e entre o autor do texto e o seu ilustrador.

A responsabilidade é considerada mista quando o conteúdo intelectual ou artístico de um documento ${ }^{3}$ recebe contribuições de diversas pessoas ou entidades coletivas, "[...] desempenhando diferentes tipos de atividade, tais como as de editor, adaptador, ilustrador, arranjador, tradutor" (CÓDIGO..., 2004, p. 21-24 ${ }^{4}$ ).

3 O Código utiliza o termo obra, porém com os FRBR outro sentido é atribuído a este termo. Portanto, substituiu-se o termo obra por documento.

${ }^{4} \mathrm{O}$ número da página citada corresponde à página 24 do capítulo 21 . Todas as demais citações do Código seguirão essa lógica, primeiro a indicação do capítulo e depois a indicação do número da página no capítulo. 
As regras dos códigos de catalogação, atualmente, passam por um processo de revisão para incorporarem os conceitos dos FRBR e os novos princípios da Declaração dos Princípios Internacionais de Catalogação. Como ainda não foram estabelecidas novas regras, a análise tem como base as regras atuais que determinam a escolha do ponto de acesso para textos traduzidos e para textos ilustrados.

Os textos traduzidos têm como ponto de acesso principal aquele determinado para o texto original (regra $21.14^{5}$ ), enquanto que o ponto de acesso secundário para o tradutor segue as prescrições de outra regra, a $21.30 \mathrm{~K} 1$, e somente será estipulado quando:

a) a tradução for em verso

b) a tradução for importante por si mesma

c) a obra tiver sido traduzida para uma mesma língua mais de uma vez

d) a redação da fonte principal de informação sugerir que o tradutor é o autor

e) os usuários do catálogo puderem ter dificuldade em encontrar o cabeçalho estabelecido para a entrada principal (p.ex., no caso de muitas obras orientais e medievais) (CÓDIGO..., 2004, p. 2146).

O tradutor tem uma importância muito grande e independente das prescrições da regra. Para os FRBR, uma obra, ao ser traduzida, resulta em uma nova expressão. A língua e o tradutor são fundamentais para delimitar obra, expressão e nova expressão.

Certos textos ganham credibilidade segundo seus tradutores. Há tradutores que se especializam em traduzir determinados autores. A tradução não implica apenas em substituir a língua original de um texto por outra, exige um grande esforço intelectual para adequar os termos e seus sentidos da língua original para a língua a ser traduzida.

Um grande empecilho para o acesso à informação é a língua. Quando o usuário não conhece a língua em que a informação está registrada, ele não decodifica a mensagem, consequentemente, não acessa a informação. Portanto, a tradução viabiliza o acesso à informação gerada em outras línguas.

A tradução é um importante fator de acesso ao conhecimento e à cultura de outras civilizações. Como bem observa Ítalo Calvino (1993, p. 36), "não foi em vão que no início do século a tradução francesa de Antoine Galland de As mil e uma noites havia aberto à fantasia ocidental os horizontes do maravilhoso oriental [...]".

Ora, a tradução é tão importante para a sociedade que não deveria ser restrita à escolha de ponto de acesso para o tradutor, que, por sua

\footnotetext{
${ }^{5}$ As regras apresentadas constam no Código de Catalogação Anglo-Americano, 2 ed. Os dois primeiros números correspondem ao número do capítulo (Capítulo 21: Escolha de pontos de acesso), os números subseqüentes e as letras indicam as subdivisões de tal capítulo.
} 
vez, possui uma grande responsabilidade sobre o texto traduzido. Da mesma forma que a escolha para o ponto de acesso para o tradutor é limitada, a escolha para o ponto de acesso secundário para o ilustrador é igualmente restritiva.

A regra que determina a escolha de pontos de acesso para textos ilustrados é a 21.11, intitulada Textos Ilustrados. Tal regra determina que, quando um ilustrador faz ilustrações a um texto, a entrada principal deve ser pelo autor do texto. A entrada secundária para o ilustrador deve seguir as prescrições da regra $21.30 \mathrm{~K} 2$. Caso haja colaboração entre 0 autor textual e o ilustrador, deve ser utilizada a regra 21.24 e, neste caso, seria considerada uma obra em colaboração entre artista e escritor, e a ambos são determinados pontos de acesso, desde que não ultrapassem quatro responsáveis com a mesma função; neste caso, aplica-se a regra 21.6C2.

Na regra para responsabilidade compartilhada por mais de três autores (regra 21.6C2), o conhecimento está personalizado no primeiro responsável citado ou no que foi indicado como principal. Se houvesse quatro ilustradores, haveria um ponto de acesso secundário para o primeiro citado e os demais seriam suprimidos e substituídos pela expressão "... [et al.]". A personalização e o reconhecimento autoral das ilustrações estariam vinculados apenas a um ilustrador.

A regra que prescreve o ponto de acesso secundário para o ilustrador é a $21.30 \mathrm{~K} 2$, e determina que semelhante ponto de acesso somente seja estabelecido quando:

a) o nome do ilustrador figurar na fonte de informação com destaque igual ao da pessoa ou entidade usada no cabeçalho da entrada principal

b) as ilustrações ocuparem metade ou mais do item

c) as ilustrações forem consideradas um aspecto importante da obra (CÓDIGO..., 2004, p. 21-46).

Os itens $a$ e $b$ desta regra estão relacionados à formatação da manifestação. A determinação do ponto de acesso está vinculada a questões editoriais. O item $c$ deixa ao critério do catalogador de atribuir importância às ilustrações.

Determinar a importância de uma contribuição intelectual ou artística segundo a formatação de uma manifestação nos parece inadequada. Se o nome consta na manifestação, isso evidencia a contribuição daquela pessoa, caso contrário nem seria citado. Independente da formatação do nome e de sua localização na manifestação, deveriam ser estabelecidos pontos de acesso para todos os responsáveis pelo conteúdo.

O trabalho intelectual assume uma nova dimensão na sociedade atual, e o estabelecimento de pontos de acesso aos responsáveis pelo conteúdo é o reconhecimento e a atribuição de uma autoria a um documento. Ao estabelecer pontos de acesso para todos os responsáveis, 
incorpora-se aos catálogos a visão de trabalho intelectual coletivo e a forma de produção do conhecimento na sociedade atual.

Dificilmente o catalogador conhecerá todos os ilustradores, a ponto de definir a importância deles e de suas ilustrações. Não se pode deixar de destacar que, algumas vezes, as pinturas e ilustrações são reconhecidas muito tempo depois de sua data de produção. Neste caso, o catalogador não poderá contar com instrumentos auxiliares (biografias, por exemplo) para definir a importância das ilustrações ou do ilustrador. Outro fator delimitador está no fato de que a ilustração deve ser considerada importante pelo usuário, e não somente pelo catalogador.

A quantidade de ilustrações em uma manifestação também não deveria ser quesito para a inclusão do ponto de acesso para o ilustrador. Ítalo Calvino exemplifica o que uma única ilustração pode causar:

Esse impulso da imaginação para além de todos os limites vai atingir seu ponto máximo no século VIII com o vôo do Barão de Münchausen numa bala de canhão, imagem definitivamente identificada em nossa memória com a obra-prima que é a ilustração de Gustave Doré (CALVINO, 1993, p. 36).

Muitas obras e expressões são reeditadas inúmeras vezes. Nem sempre as novas edições têm as mesmas ilustrações ou têm ilustrações criadas pelo mesmo ilustrador das edições anteriores. Os livros infantis de Monteiro Lobato são constantemente reeditados e a cada nova edição é possível observar diferenças nos traços das ilustrações. A atribuição dos créditos ao ilustrador é diferente nas várias edições (expressões) da mesma obra de Monteiro Lobato.

Uma ilustração pode representar muitas coisas, inclusive a mudança do imaginário de uma sociedade. Como já dito acima, uma ilustração pode ser reconhecida ou ter seu valor estimado muito tempo depois de sua criação. A elaboração do registro bibliográfico possibilita o uso imediato e futuro de uma informação. Excluir os pontos de acesso dos responsáveis pelo conteúdo artístico inscrito em uma manifestação impediria a recuperação de informações para os usuários atuais e também para os usuários futuros do catálogo.

Ao determinar pontos de acesso aos tradutores e aos ilustradores, atribui-se responsabilidade autoral a um documento. A questão autoral pode ser discutida em vários segmentos; na catalogação ela envolve a escolha, a padronização do ponto de acesso e o reconhecimento de um autor. A determinação da responsabilidade segue preceitos e, em geral, a principal fonte para ao reconhecimento da autoria é a página de rosto. Mesmo com os códigos de catalogação e com a página de rosto, o catalogador pode encontrar dificuldades para atribuir autoria e para escolher os pontos de acesso. As dúvidas sobre a autoria tendem a ser tornarem mais complexas.

Na Internet, por exemplo, cada indivíduo pode assumir várias identificações ao mesmo tempo: todos podem ser autores, 
agentes, produtores, editores, leitores, consumidores, de um modo em que a subjetividade de cada papel prevalece de acordo com o instante. Nesse sentido, os papéis se misturam e se confundem, distanciando-se de suas caracterizações tradicionais e colocando em discussão a reorganização desses temas (ANTONIO, 1998, p. 190).

A análise do documento a ser descrito exige um esforço mental, assim como os códigos precisam incorporar as mudanças na produção do conhecimento. Uma visão tecnicista pode aceitar somente os autores contidos na página de rosto, mesmo que o sumário ou outra parte da publicação evidencie claramente a presença de outros autores.

De fato, a representação da informação deve corresponder ao documento, não apenas à página de rosto. Em muitas áreas e grupos de pesquisa opta-se pela ordenação alfabética de autores, portanto a ordem de citação não corresponde à importância da contribuição intelectual a um documento. Na catalogação, quando não há indicação do autor principal (e se houver mais de três autores citados), haverá ponto de acesso apenas para o primeiro. Isso revela que as normas não acompanham a função de autor e a autoria na produção de conhecimento da sociedade atual.

\section{Considerações finais}

Os FRBR ampliam as dimensões das responsabilidades sobre os conteúdos de uma obra ou expressão. Com isso, a relação do catálogo com a autoria se altera. A produção do conhecimento está muito voltada a trabalhos intelectuais coletivos e os FRBR redefinem a importância dos responsáveis pelo conteúdo de uma obra ou expressão, e atribuem maior importância a eles. Ou seja, os FRBR traduzem as alterações sociais paras as possibilidades de representação da informação nos registros bibliográficos.

O usuário deve ser capaz de encontrar uma entidade quando conhecer o seu responsável pelo conteúdo intelectual ou artístico. O estabelecimento de pontos de acessos para todos os responsáveis pelo conteúdo intelectual ou artístico inscritos nas manifestações beneficia a busca e a recuperação feitas pelos usuários, e contempla as questões relacionadas aos direitos autorais, pois valoriza a propriedade intelectual ou artística de uma pessoa ou entidade coletiva. No mesmo instante em que personaliza o conhecimento para além do primeiro responsável citado, quando há mais de três, também reconhece a personalização do conhecimento quando há responsabilidade mista, no caso de tradutores e ilustradores que são responsáveis pelo surgimento de novas expressões de uma obra.

Anteriormente as regras eram estipuladas para facilitar o trabalho do profissional, com os FRBR as regras devem ser estipuladas para facilitar as atividades dos usuários. Esta mudança implica a revisão das regras, entre elas a da escolha dos pontos de acesso. As regras sobre os pontos de acesso devem ser rígidas na forma (controle de vocabulário), 
enquanto que a escolha dos pontos de acesso será livre para que cada instituição atenda melhor seu público.

Muitas alterações deverão acontecer nas regras, principalmente naquelas relacionadas à escolha dos pontos de acesso para os responsáveis pelo conteúdo inscrito em um documento. As regras que estabelecem e limitam a escolha dos pontos de acesso estão direcionadas à confecção de catálogos impressos, enquanto que os FRBR são um modelo conceitual entidade-relacionamento utilizado para a construção de bases de dados computacionais.

Os FRBR trazem um novo olhar sobre a catalogação, ampliando, principalmente, a visão de responsabilidade intelectual e artística em um documento, e destacando a atividade do profissional como uma atividade que agrega teoria e prática. Rompendo, dessa forma, com a crença de que a catalogação é uma atividade puramente técnica.

\section{Referências}

ANTONIO, I. Autoria e cultura na pós-modernidade. Ciência da Informação, Brasília, v. 27, n. 2, p. 189-192, maio/ago. 1998.

CALVINO, I. Seis propostas para o próximo milênio. São Paulo: Companhia das Letras, 1993.

CHEN, P. Modelagem de dados: a abordagem entidade-relacionamento para projeto lógico. São Paulo: McGraw-Hill, 1990.

CÓDIGO de Catalogação Anglo-Americano. 2 ed. rev. 2002. São Paulo: FEBAB, 2004.

CUTTER, C. A. Rules for a dictionary catalog. 4 ed. Washigton, D.C.: Printing Office, 1904 apud MEY, E. S. A. Introdução à catalogação. Brasília: Briquet de Lemos/Livros, 1995.

DECLARACIÓN de Principios Adoptados por la Conferencia Internacional sobre Principios de Catalogación París. Octubre de 1961. In: REUNIÓN IFLA DE EXPERTOS SOBRE UN CÓDIGO INTERNACIONAL DE CATALOGACIÓN, 2., 2004. Papers. Buenos Aires: [s.n.], 2004. Disponível em: <http://www.loc.gov/loc/ifla/imeicc/papers-sp.html>. Acesso em: 18 out. 2006.

INTERNATIONAL FEDERATION OF LIBRARY ASSOCIATIONS (IFLA). Declaração de Princípios Internacionais de Catalogação. 2009. Disponível em: <www.ifla.org/VII/s13/icp/>. Acesso em: 18 abr. 2009.

INTERNATIONAL FEDERATION OF LIBRARY ASSOCIATIONS (IFLA). STUDY GROUP ON THE FUNCTIONAL REQUIREMENTS FOR BIBLIOGRAPHIC RECORDS. Functional requirements for bibliographic records: final report. UBCIM Publications - New Series, vol. 19. München: K. G. Saur, 1998. Disponível em: <www.ifla.org>. Acesso em: 16 ago. 2006.

MEY, E. S. A. Introdução à catalogação. Brasília: Briquet de Lemos/Livros, 1995. 
MORENO, F. P. Requisitos Funcionais para Registros Bibliográficos - FRBR: um estudo no catálogo da Rede Bibliodata. 2006. Dissertação (Mestrado em Ciência da Informação) - Universidade de Brasília, Brasília, 2006.

ORTEGA, C. D. Relações entre Biblioteconomia, Documentação e Ciência da Informação. Datagramazero, v. 5, n. 5, out. 2004. Disponível em: < http://www.dgz.org.br/out04/F I art.htm>. Acesso em: 12 maio 2006.

SAGREDO, F.; NUÑO, M. V. En los orígenes de la Biblioteconomía y Documentación: Ebla. Documentación de las Ciencias de la Información, Madrid, n. 17, p. 123-129, 1994 apud ORTEGA, C. D. Relações entre Biblioteconomia, Documentação e Ciência da Informação. Datagramazero, v. 5, n. 5, out. 2004. Disponível em: <http://www.dgz.org.br/out04/F I art.htm>. Acesso em: 12 maio 2006.

TILLETT, B. O que é FRBR? : um modelo conceitual para o universo bibliográfico. Technicalities, v. 25, n. 5, Sept./Oct. 2003. Disponível em: $<$ http://www.snake.ne.jp/ yama/nph-

docomo.cgi/010000A/http/www.loc.gov/catdir/cpso/o-que-e-frbr.pdf>. Acesso em: 12 maio 2007. 